University of New Hampshire

University of New Hampshire Scholars' Repository

7-2008

\title{
Very Shallow Water Bathymetry Retrieval from Hyperspectral Imagery at the Virginia Coast Reserve (VCR'07) Multi-Sensor Campaign
}

\author{
Charles M. Bachmann \\ U.S. Naval Research Laboratory \\ Marcos J. Montes \\ U.S. Naval Research Laboratory \\ Robert A. Fusina \\ U.S. Naval Research Laboratory \\ Christopher Parrish \\ University of New Hampshire, Durham \\ Jon Sellars \\ NOAA
}

Sellonv this and fadditionahwarks at: https://scholars.unh.edu/ccom

Part of the Computer Sciences Commons, and the Oceanography and Atmospheric Sciences and Meteorology Commons

\section{Recommended Citation}

C. M. Bachmann et al., "Very shallow water Bathymetry retrieval from Hyperspectral imagery at the Virginia Coast reserve (VCR'07) multi-sensor campaign," IGARSS 2008 - 2008 IEEE International Geoscience and Remote Sensing Symposium, 2008.

This Conference Proceeding is brought to you for free and open access by the Center for Coastal and Ocean Mapping at University of New Hampshire Scholars' Repository. It has been accepted for inclusion in Center for Coastal and Ocean Mapping by an authorized administrator of University of New Hampshire Scholars' Repository. For more information, please contact Scholarly.Communication@unh.edu. 


\section{Authors}

Charles M. Bachmann, Marcos J. Montes, Robert A. Fusina, Christopher Parrish, Jon Sellars, Alan Weidemann, Wesley Goode, C Reid Nichols, Patrick Woodward, Kevin Mcllhany, Victoria Hill, Richard Zimmerman, Daniel Korwan, Barry Truitt, and A. Schwarzschild 


\title{
VERY SHALLOW WATER BATHYMETRY RETRIEVAL FROM HYPERSPECTRAL IMAGERY AT THE VIRGINIA COAST RESERVE (VCR'07) MULTI-SENSOR CAMPAIGN
}

\author{
$\dagger$ Charles M. Bachmann, $\nmid$ Marcos J. Montes, $†$ Robert A. Fusina, $† \dagger$ Christopher Parrish, $\dagger \dagger$ Jon Sellars \\ $\ddagger$ Alan Weidemann, †Wesley Goode, ${ }^{*}$ C. Reid Nichols, *Patrick Woodward, \#Kevin McIlhany \\ ++ Victoria Hill, ++Richard Zimmerman, †Daniel Korwan, **Barry Truitt, +Arthur Schwarzschild
}

†Naval Research Laboratory, Remote Sensing Division, Washington, DC 20375 (bachmann@nrl.navy.mil)

\author{
$\dagger \dagger$ NOAA NOS, Silver Spring, MD \\ $\ddagger$ Naval Resarch Laboratory, Oceanography Division, Stennis, MS \\ *Marine Information Resources Corporation, Ellicott City, MD \\ \# US Naval Academy, Physics Department, Annapolis, MD \\ ++ Old Dominion University \\ **The Nature Conservancy, Nassawaddox, VA \\ +University of Virginia, Dept. of Environmental Science, Charlottesville, VA
}

\begin{abstract}
A number of institutions, including the Naval Research Laboratory (NRL), have developed look up tables for remote retrieval of bathymetry and in-water optical properties from hyperspectral imagery (HSI) [6]. For bathymetry retrieval, the lower limit is the very shallow water case (here defined as $<2 \mathrm{~m}$ ), a depth zone which is not well resolved by many existing bathymetric LIDAR sensors, such as SHOALS [4]. The ability to rapidly model these shallow water depths from HSI directly has potential benefits for combined HSI/LIDAR systems such as the Compact Hydrographic Airborne Rapid Total Survey (CHARTS) [10]. In this study, we focused on the validation of a near infra-red feature, corresponding to a local minimum in absorption (and therefore a local peak in reflectance), which can be correlated directly to bathymetry with a high degree of confidence. Compared to other VNIR wavelengths, this particular near-IR feature corresponds to a peak in the correlation with depth in this very shallow water regime, and this is a spectral range where reflectance depends primarily on water depth (water absorption) and bottom type, with suspended constituents playing a secondary role.
\end{abstract}

Index Terms - hyperspectral, shallow-water bathymetry, bottom type, IOP, Hydrolight, Virginia Coast Reserve

\section{INTRODUCTION AND BACKGROUND}

At visible and near infra-red (VNIR) wavelengths, reflectance is determined by a variety of factors including water depth, bottom type, and the presence of suspended constituents such as color-dissolved organic matter (CDOM), suspended sediments, chlorophyll, phytoplankton, and other suspended constituents [6]. Thus the general problem of retrieving depth

The NRL authors gratefully acknowledge platform support from the Office of Naval Research. This paper was funded by the National Geospatial-Intelligence Agency (NGA). The opinons, views, and conclusions found within the paper do not necessarily reflect those of the U.S. Dept. of Defense or the NGA. as well as other water properties has been approached using spectral look-up tables [7] in which a forward radiative transfer model such as Hydrolight [8] is executed repeatedly with varying water column properties, depth, and bottom types. To be comprehensive, these look-up tables must be large and may need to be tuned to specific coastal types because of variability in bottom types and water properties which may vary significantly with coastal type. An attractive feature of hyperspectral data is the enhanced capability to simultaneously serve a multitude of uses, in addition to bathymetry retrieval. Light Detection and Ranging (LIDAR) has also been widely used to retrieve bathymetric data. LIDAR has the advantage that it is an active sensor, which may provide greater accuracy in deeper waters, however, LIDAR systems such as the Scanning Hydrographic Operational Airborne Lidar Survey (SHOALS) [4] must be flown at very low altitude with a relatively small swath compared to typical airborne hyperspectral sensors. In the very shallow water regime (less than $2 \mathrm{~m}$ depth), LIDAR systems often do not provide a reliable retrieval, failing to resolve the difference between the bottom and surface returns. In this paper, we focus on this very shallow water regime, specifically on the retrieval of bathymetry from a spectral range where a relatively simple model for reflectance can be assumed. Compared to the reflectance at visible wavelengths, where all contributions from the water column must be carefully considered, near infra-red wavelength reflectance (beyond $800 \mathrm{~nm}$ ) is primarily dependent on water absorption and depth, along with bottom reflectance, with water column constituents playing a secondary role. 


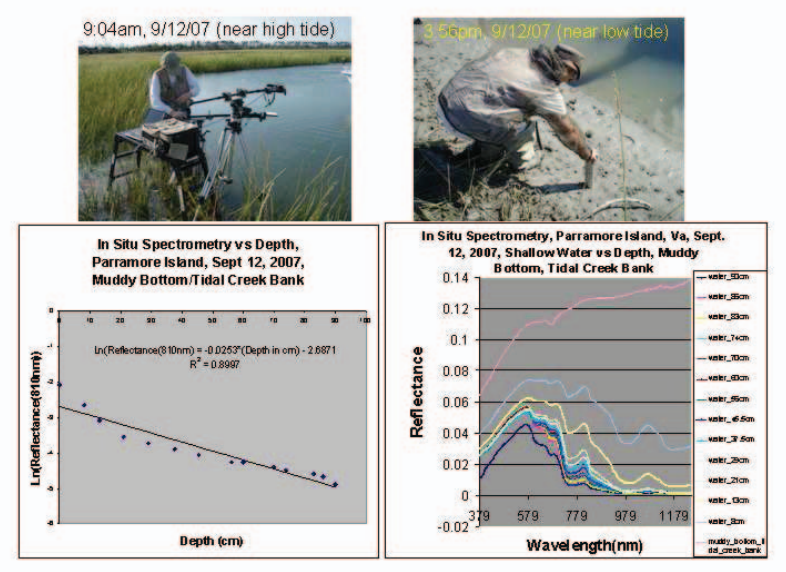

Fig. 1. (Top) Parramore Island in situ spectrometry site on salt marsh tidal creek bank with muddy bottom: (left) beginning (near high tide), (right) end (near low tide) of measurement cycle. (Bottom right) Spectral samples at depths varying from $89 \mathrm{~cm}$ to $0 \mathrm{~cm}$ (wet substrate). (Bottom left) $\ln \left(R_{810 \mathrm{~nm}}\right)$ vs $d$ (depth in $\left.\mathrm{cm}\right)$.

\section{VIRGINIA COAST RESERVE CAMPAIGN}

In September 2007, NRL and a number of collaborating institutions undertook a multi-sensor airborne data collection and in situ validation campaign at the Virginia Coast Reserve (VCR'07). Airborne, in-water, and land based measurements took place over the course of the $2 \frac{1}{2}$ week exercise and covered a $95 \mathrm{~km}$ stretch of barrier islands, coastal lagoons, tidal flats, and mainland marsh systems. NRL flew three sensors on a Twin Otter aircraft: a CASI-1500 visible and near infra-red (VNIR) HSI sensor, a Surface Optics InGaAs SWIR HSI sensor operating in the 0.9-1.7 $\mu \mathrm{m}$ spectral region, and single channel mid-wave IR camera. This paper focuses on the CASI imagery taken during the experiment, and the in situ validation data collected to study the NIR feature described above (other littoral focus areas studied during the VCR'07 experiment included the remote retrieval of soil bearing strength [2], biomass retrieval, land-cover mapping [1], as well as seagrass and oyster reef monitoring).

For the very shallow bathymetry study, field validation efforts used Analytical Spectral Devices (ASD) spectrometers positioned on a tripod in a shallow cove behind Wreck Island, VA, and in the shallow stretches of a muddy tidal creek and salt marsh system in the northern end of Parramore Island, VA. Depth and ASD spectral measurements were recorded on a falling tide until the substrate was completely exposed, allowing an in situ bottom reflectance to be obtained in the measurement suite. Bottom reflectance was also measured by divers using an underwater spectrometer at other locations. Previously, during field work in October 2005, ASD measurements had been collected in the shallow waters on the edge of a salt marsh system in the northern end of Smith Island. Dur-

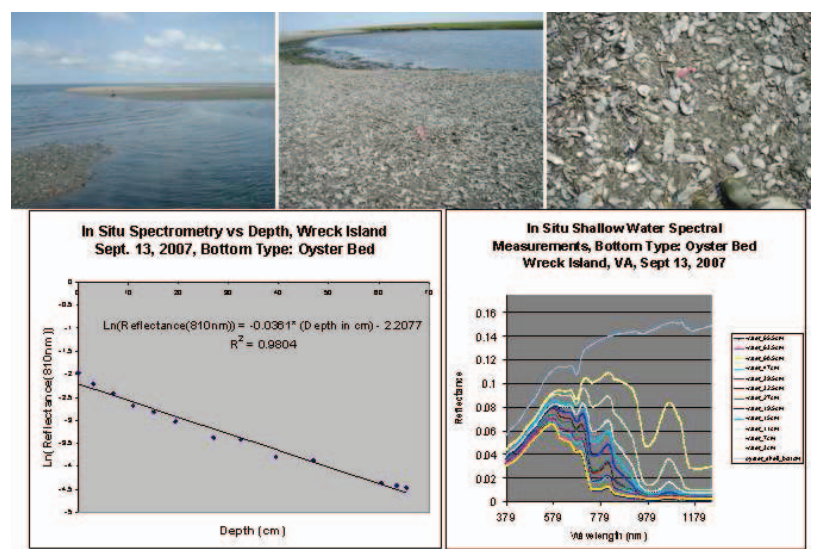

Fig. 2. Wreck Island in situ spectrometry site with oyster bed bottom in a shallow cove. (Top) Site photos. (Bottom right)Spectral samples at depths varying from $86 \mathrm{~cm}$ to $0 \mathrm{~cm}$ (wet substrate); (bottom left) $\ln \left(R_{810 n m}\right)$ vs $d$ (depth in $\mathrm{cm}$ ) and associated regression.

ing VCR'07, Kinematic GPS data were taken in the inter-tidal region on the northern end of Wreck Island to support product validation. In addition, depth soundings were taken in the shallow waters behind the island and in the adjacent channel separating Wreck from Cobb Island. At the conclusion of the study, the NASA EAARL LIDAR took data in conjunction with the NRL sensor suite, albeit during a period when weather conditions were not optimal, and turbidity was high.

Figures 1 and 2 show the measured spectral curves for each depth collected during the measurement cycle at Parramore and Wreck Islands respectively, along with in situ photos and the regression at the $810 \mathrm{~nm}$ feature. A similar regression was carried out for data taken at Smith Island, VA in October 2005 for a sand/silt bottom on the watery margin between beach and salt marsh zones. As described earlier the focus was on the longer wavelengths of the near infra-red spectrum, but the full range spectrum from 0.35-2.5 microns was also collected. Note that the visible and near infra-red are the portions of the spectrum usually used in water applications, since the reflectance beyond a micron is near zero, except when constituents in the water column are fully mixed to the surface layer. The visible spectrum shows a relatively broad peak near $810 \mathrm{~nm}$, corresponding to a local minimum in the liquid water absorption [3]. There is a similar peak near 1.076 microns, which is of a similar origin, though less pronounced character. To assess the relative merits of wavelength selection at these longer wavelengths and confirm the optimality of the choice of the $810 \mathrm{~nm}$ feature, we computed an $R^{2}$ goodness of fit between a linear regression of $\ln \left(R_{\lambda}\right)$ and $d$, where $R_{\lambda}$ is the reflectance at wavelength $\lambda$, and $d$ is the depth in $\mathrm{cm}$. Figure 3 shows plots of this feature across the full spectrum for each of the two sites, with enlargements of the VNIR portion of the spectrum. The best correlation occurs near two peaks, one at $810 \mathrm{~nm}$ and the other near $720 \mathrm{~nm}$. 

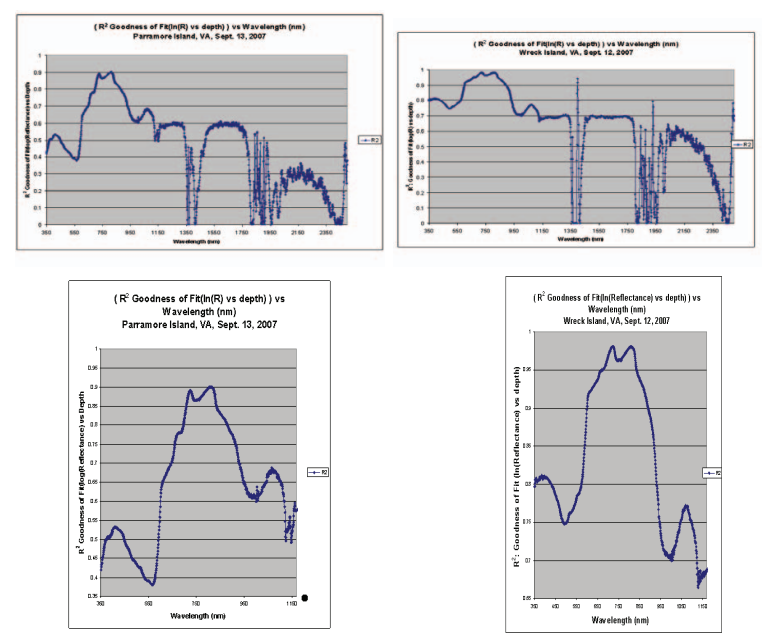

Fig. 3. $R^{2}$ fit of $\ln \left(R_{\lambda}\right)$ and $d$ for: (left column) Muddy bottom, Parramore Island, (right, column)oyster bed bottom, Wreck Island. (Top row) 0.35-2.5 $\mu \mathrm{m}$, (bottom row) enlargement of 0.35-1.07 $\mu \mathrm{m}$.

Wavelengths between these two peaks would work well also, but the best fit with $R^{2}$ values near 0.89 (muddy bottom) and 0.98 (oyster shell bed bottom) for Parramore Island and Wreck Island respectively are near these two wavelengths. In the VNIR spectrum below $800 \mathrm{~nm}$, the $R^{2}$ fit for the oyster shell bottom case (Wreck Island), $R^{2}$ never exceeds $\sim 0.81$ (at $384 \mathrm{~nm}$ ) compared to the peaks at $721 \mathrm{~nm}$ and $809 \mathrm{~nm}$ where $R^{2} \sim 0.98$, while for the muddy bottom case (Parramore Island), the $R^{2}$ never exceeds $\sim 0.53$ (at $409 \mathrm{~nm}$ ), compared to the peaks at $725 \mathrm{~nm}\left(R^{2}=0.891\right)$ and $811 \mathrm{~nm}\left(R^{2}=0.900\right)$. Spectral stability and high $R^{2}$ of the $810 \mathrm{~nm}$ feature for both dark and bright bottom cases, demonstrate its optimality. In contrast, at visible wavelengths, the best $R^{2}$ is not at a stable location and is only moderately good for bright bottoms.

\section{HYDROLIGHT MODELS}

To demonstrate that varying concentrations of suspended constituents does not significantly impact the reflectance at 810 $\mathrm{nm}$ but indeed is a large contributing factor to the shorter wavelength returns, we have run a series of models using Hydrolight [8]. This model allows us to vary the concentration of constituents, bottom type, depth, (etc) and look at the contribution to remote sensing return as a function of wavelength. In this Section, we show that varying suspended constituents is indeed expected to make only a small difference near $810 \mathrm{~nm}$, while at shorter wavelengths in the visible, these changes have a significant impact that can not be ignored in modeling. Figure 5 illustrates this point for a case in which total suspended sediment (TSS) is varied while all other inherent optical properties (IOP's) are held fixed and the depth is constant for a specific bottom type (in this case, the field spectrum of our bottom substrate reflectance taken for the oys-
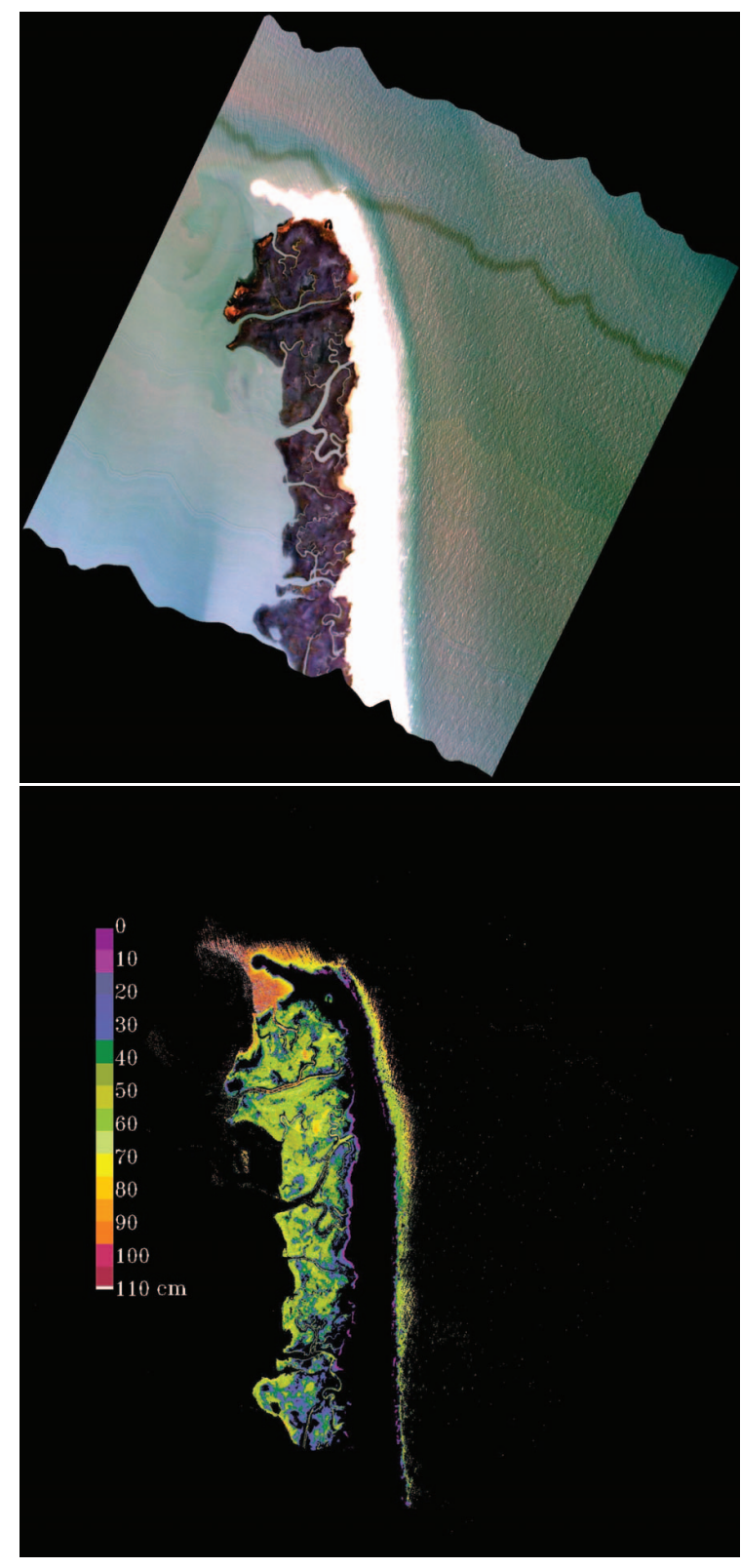

Fig. 4. (Top) NRL CASI-1500 image of Wreck Island (9:45am line). (Middle) Retrieved depth using the $810 \mathrm{~nm}$ regressions for each bottom type determined in preprocessing from the spectral libraries. Depth is quantized in the color scale, but retrieval is continuous. 


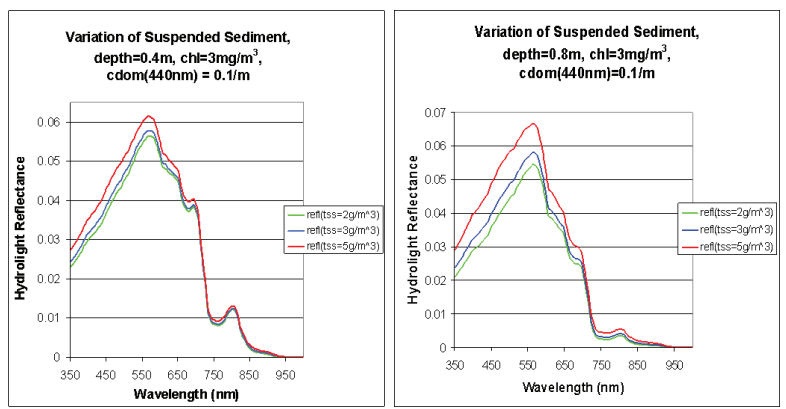

Fig. 5. Simulated reflectance using Hydrolight, for varying TSS, with all other IOP's held fixed, at depths: (left) $0.4 \mathrm{~m}$, (right) $0.8 \mathrm{~m}$.

ter bed depth vs ASD profiles at Wreck Island described earlier). We provide two examples, one at a fixed depth of $0.4 \mathrm{~m}$ and the other at $0.8 \mathrm{~m}$. Hydrolight reflectances are shown for $\mathrm{TSS}=2,3$, and $5 \frac{\mathrm{g}}{\mathrm{m}^{3}}$. Note the much larger variation in reflectance at wavelengths below $700 \mathrm{~nm}$ compared to longer wavelengths. This example supports our earlier contention that suspended constituents make a secondary contribution at wavelengths such as $810 \mathrm{~nm}$ and $725 \mathrm{~nm}$, which are the ideal wavelength ranges for regressions between the logarithm of reflectance and depth as illustrated in Figure 3.

\section{BATHYMETRY RETRIEVAL}

During VCR'07, the NRL CASI-1500 acquired imagery over Wreck Island at eight different times. Two of these scenes were acquired on the same day and during the sampling window for in situ spectral sampling on Wreck Island on September 13, 2007. The first of these scenes was acquired on a falling tide roughly 15 minutes prior to the first ASD spectral sampling (Figure 4). Although various atmospheric correction models were explored using the NRL Tafkaa atmospheric correction program [9], an empirical line calibration was ultimately used, aligning the spectral data from the CASI with ASD data taken both in the water (dark pixel) for the depth vs ASD profiles and those that were being acquired for substrate studies [2] on the beach nearby (bright pixels).

Data were initially segmented using scene based regions of interest designed to separate out the deep water pixels from shallow water pixels. This step involved maximum likelihood classification to trim off deep water pixels from the scene. For the remaining shallow water data, prior to applying the $810 \mathrm{~nm}$ regressions, the data were partitioned by bottom type using a spectral angle mapper [5] criterion which matched the CASI imagery pixels to the closest ASD profile found in the in situ profiles taken by us during VCR'07 and in October 2005 as just described. During this phase of the processing, a moderate angle was sufficient to generate a reasonable delineation of bottom types in the scenes. Three bottom types described earlier, oyster bed, muddy bottom, and sand/silt mixture were used and were based on the ASD vs depth profile spectral libraries obtained at Parramore, Wreck, and Smith Islands. Retrievals using the $\ln \left(R_{\lambda}\right)$ vs $d$ regressions for the $810 \mathrm{~nm}$ for each bottom were applied separately to the data after segementation by bottom type. The resulting depth retrieval in centimeters is shown in Figure 4. Although the bathymetry retrieval is real-valued, in Figure 4, the retrieval has been quantized (see the accompanying color bar) to better highlight bathymetric structure. Note that the retrieval is applied successfully in the shallow cove, the shallow ocean side in the surf zone, as well as in the salt marsh and tidal creeks in the western portion of the image. The salt marsh vegetation is dominated by Spartina alterniflora, an erectophile canopy which allows for significant substrate exposure, and when inundated, a significant fraction of the pixel appears as water in a nadir view. This allows the $810 \mathrm{~nm}$ retrieval to be used successfully in these regions via the muddy bottom regression.

\section{CONCLUSIONS}

We have shown the potential of a near infra-red feature centered near $810 \mathrm{~nm}$ for retrieving very shallow water bathymetry $(<2 \mathrm{~m}$ depth). Because this portion of the spectrum is predominantly influenced by water absorption (depth) and the reflectance of the bottom, effects of suspended constituents have only a secondary contribution, allowing us to use a set of simple regressions based on bottom type, rather than a full radiative transfer model in the very shallow water regime. Operational LIDAR systems such as SHOALS do not produce reliable retrievals in the very shallow water regime, and in joint HSI/LIDAR platforms such as CHARTS, the new approach could fill a gap in bathymetric retrieval.

\section{REFERENCES}

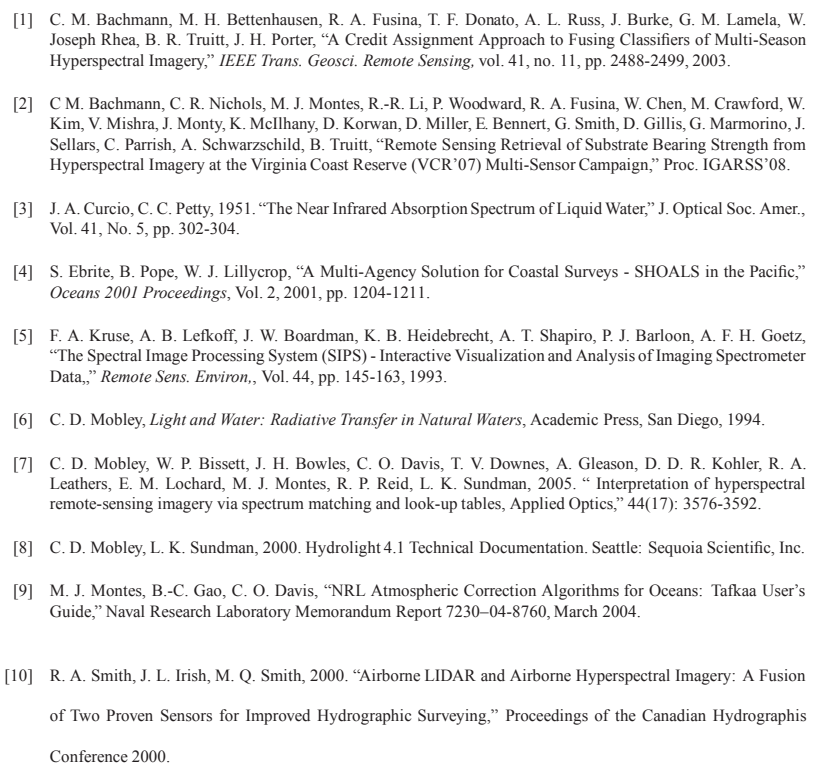

] C. M. Bachmann, M. H. Bettenhausen, R. A. Fusina, T. F. Donato, A. L. Russ, J. Burke, G. M. Lamela, W. Joseph Rhea, B. R. Truitt, J. H. Porter, "A Credit Assignment Approach to Fusing Classifiers of Multi-Seaso

C M. Bachmann, C. R. Nichols, M. J. Montes, R.-R. Li, P. Woodward, R. A. Fusina, W. Chen, M. Crawford, W. Kim, V. Mishra, J. Monty, K. Mcllhany, D. Korwan, D. Miller, E. Bennert, G. Smith, D. Gillis, G. Marmorino, J. Hellars, C. Parrish, A. Schwarzschild, B. Truitt, "Remote Sensing Retrieval of Substrate Bearing Strength from
Hyperspectral Imagery at the Virginia Coast Reserve (VCR'07) Multi-Sensor Campaign," Proc. IGARSS'08.

3] J. A. Curcio, C. C. Petty, 1951. "The Near Infrared Absorption Spectrum of Liquid Water," J. Optical Soc. Amer.,

S. Ebrite, B. Pope, W. J. Lillycrop, "A Multi-Agency Solution for Coastal Surveys - SHOALS in the Pacific,"

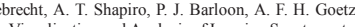
Data," Remote Sens. Environ, Vol. 44, pp. 145-163, 1993.

A. Kohler, R. A. Leathers, E. M. Lochard, M. J. Montes, R. P. Reid, L. K. Sundman, 2005. "Interpretation of hyperspect

8] C. D. Mobley, L. K. Sundman, 2000. Hydrolight 4.1 Technical Documentation. Seattle: Sequoia Scientific, Inc. M. J. Montes, B.-C. Gao, C. O. Davis, “NRL Atmospheric Correction Algorithms for Oceans: Tafkaa User's Guide," Naval Research Laboratory Memorandum Report 7230-04-8760, March 2004.

Conference 2000. 